\title{
APUNTES SOBRE LA ACTIVIDAD \\ MISIONERA JUNTO AL PUEBLO \\ MAPUCHE DESPUÉS DEL VATICANO ॥
}

Fernando Diaz, SVD

La pregunta por la historia de la evangelización del pueblo mapuche es mucho más que una simple procura de datos sobre hechos y personaje del pasado. Es sobre todo el esfuerzo por comprender los que esta sucediendo en el presente. La compleja situación religiosa del pueblo mapuche en la actualidad desafia cualquier explicación. Por lo mismo, cualquier iniciativa pastoral precisa de una continua referencia a los procesos históricos. Actualmente se están desarrollando y publicando interesantes estudios sobre historia y evangelización del pueblo mapuche. Mediante este trabajo, pretendo recoger algunos antecedentes y ofrecer algunos elementos para la reflexión de la actividad misionera junto al pueblo mapuche.

\section{A. INTRODUCCIÓN}

La Iglesia Católica forma parte de una historia en que la conquista y la actividad misionera se entrelazan fatalmente. Un proceso marcado por la violencia y la brutalidad que determinará profundamente las relaciones entre mapuche y chilenos. ${ }^{1}$ Lo que el autor José Bengoa define como una "historia acerca de la intolerancia' ${ }^{\prime 2}$ indica el meollo de lo que ha sucedido durante la

1 JOSÉ BENGOA dedica su texto "Conquista y Barbarie" a este tema, mostrando como la violencia del inicio definió una relación que se proyectó a lo largo de toda la historia: "en el inicio de la conquista se estableció el odio ...". Cfr J. BENGOA. Conquista y barbarie. Ensayo critico acerca de la conquista de Chile, Ed. Sur, Col. Estudios Históricos, Santiago 1992, p. 45.

2. "Esta es una historia acerca de la intolerancia. Acerca de una sociedad que no soporta la existencia de gente diferente, y trato de acabar con los hombres que deambulaban libremente por las pampas y cordilleras del sur del continente. Ellos se defendieron del salvajismo civilizado ..." J. BENGOA, Op. cit. p. 5. 
conquista y la colonización. Intolerancia que de muchos modos continúa sucediendo.

El pueblo mapuche tiene su versión de esa historia, no en libros ni documentos escritos, sino codificada en mitos y relatos, en ritos y tradiciones. Se trata sobre todo de un conjunto articulado de diversas formas de resistencia. de sueños y esperanzas que se han ido transmitiendo de una generación a otra y que vehiculan una identidad y un proyecto histórico propios. En la medida que los preconceptos van cayendo y la ciencias sociales han ido mostrando nuevos aspectos del pasado, ha sido posible rescatar la historia de los que se supone, perdieron la guerra. Ese esfuerzo no es sin significado, no es mera arqueologia. El solo hecho que hoy en dia en Chile, en el censo de 1992, alrededor de un millón de personas, se identificaron como mapuche, provocó una gran sorpresa a investigadores y a la población en general. El pueblo mapuche, aún siendo una minoria, es el elemento más significativo en la construcción de la identidad nacional. Negado de diversas formas, su ser diferente, su resistencia a todo tipo de asimilación, y el hecho de ser parte constitutiva del origen y del presente de la sociedad chilena, lo convierte en un desafio permanente y en la posibilidad real de avanzar hacia una sociedad plural y equitativa.

Para la evangelización, el mapuche es la denuncia permanente del fracaso de una Iglesia de cristiandad que. ligada históricamente al poder colonial, perdió el significado del Evangelio como mensaje de vida y de liberación. La propuesta de una "nueva evangelización" obliga a repensar las categorias y modelos desde los que se pretende realizar esta tarea. La misión, con su hipoteca colonial, es vista con desconfianza por diversos sectores sociales, incluyendo organizaciones de los mismos indigenas. La misión necesita más que nunca aclarar sus intenciones y su propuestas frente a un pueblo que continúa amenazado por nuevos modelos sociales, económicos y religiosos, que pretenden nuevamente incorporarlo para brindarle la salvación. Si bien es verdad que en el presente un alto porcentaje de mapuche se bautiza, no parece haber indicios de alguna iglesia local en la cual, la fe católica haya llegado a expresarse en códigos culturales mapuche. En general el sistema religioso mapuche es considerado apenas como "religiosidad" o como "tradiciones y costumbres". En pocas palabras, la actividad misionera en general, continúa realizándose en un cierto conflicto con la cultura mapuche, a pesar de ella y no a partir de elia. El cristianismo ha sido impuesto culturalmente, pero la iglesia sigue siendo extraña a la cultura mapuche.

Nuestra percepción es que la Iglesia católica en Chile históricamente se ha quedado presa en las estructuras culturales y en los mecanismos de dominación impuestos por los colonizadores y todavia no logra generar las condiciones para que surja una iglesia local inculturada. Su lenguaje, sus estructuras, sus propuestas, se confundieron dramáticamente con el proyecto colonial de "civilización". Sin despreciar el esfuerzo sincero ni el celo apostólico de tantos misioneros que ha pasado por esas tierras, se 
puede afirmar que en la práctica, el desconocimiento, y más aún, el desprecio por la cultura y la sociedad mapuche como tal, le cerraron los ojos frente a la profunda experiencia de Dios en el pueblo mapuche. La disociación entre celo misionero y reconocimiento del otro en su alteridad cultural, terminó siendo fuente de profunda injusticia. Actualmente, la descalificación se realiza mediante la imposición de modelos pastorales y catequéticos generados en realidades totalmente diferentes a la mapuche. Como si los mapuche no tuvieran un sistema religioso distinto vigente.

Con los cambios en la percepción de su ministerio eclesial y de su relación con la diversidad de culturas a partir del Vaticano II, la Iglesia latinoamericana, comenzó ha repensar profundamente su acción pastoral con los pueblos indigenas. La esperanza de una iglesia que pretende ser fiel a su vocación misionera es llegar a ser algún día realmente compañera en el camino de liberación del pueblo mapuche.

\section{B. Antecedentes Generales}

Las décadas del 60, época en que se realizó el Concilio Vaticano II, fueron de gran agitación en el sector mapuche rural, a causa de la expectativa que creo la reforma agraria. La recuperación de tierras usurpadas continuaba siendo una demanda sentida por los mapuches. Se produjo un gran movimiento que se expresó en tomas de terrenos en toda la región mapuche. Dos grandes congresos nacionales en 1969 y 1970 dejaron clara la reivindicación principal: la tierra. La Ley indigena de 1971 recogiendo la demanda mapuche, viabilizó la recuperación de tierras usurpadas y detuvo la división y enajenación de tierras indígenas que venía aconteciendo. Eliminó los Juzgados de Indios y creó el Instituto de Desarrollo Indigena (IDI). Los mapuches recuperaron un total de 68.381 hectáreas ${ }^{3}$. Hacia 1972 habia más de 40 organizaciones representando al pueblo mapuche.

Pero en 1973, tras el golpe de estado, el gobierno militar, salvo contadas excepciones, devolvió todas las tierras a los anteriores dueños, desalojando a los indigenas, reprimiendo y desarticulando sus organizaciones ${ }^{4}$.

En 1979 decretó una reforma de la Ley indigena, con el objetivo claro, de eliminar las comunidades mapuches. Para esto impulsó la división de las tierras comunitarias y la entrega de títulos de propiedad privada. Con esto los mapuches pasaban a ser propietarios individuales y dejaban de ser indigenas. Dejándolas estratégicamente desprotegidas, muchas tierras

J. AYLWIN, "Antecedentes histórico-legislativos para el estudio de comunidades reduccionales mapuche", en Pentukun 4(1995)32-33.

Cfr E. GACITÚA, "Hacia un marco interpretativo de las movilizaciones mapuches en los últimos 17 años". en Nütram 28, Año VIII. (1992) 22-44. 
fueron arrendadas por 99 años. Desaparecieron asi casi la totalidad de las propiedades comunitarias y con ello la posibilidad de recuperar o ampliar las tierras indigenas.

El crecimiento de la población rural mapuche y la insuficiencia de tierras, fortaleció el proceso migratorio a los centros urbanos. En 1992 el censo nacional mostró que solo en la ciudad de Santiago, hay más de 400 mil mapuche, o sea casi el $50 \%$ del total de mapuche del pais.

Pero la nueva ley de división de tierras. provocó que las comunidades mapuches se organizaran y presentaran sus demandas. Desde esa época comenzaron a surgir nuevamente un sinnumero de organizaciones mapuches, que más tarde en el proceso de redemocratización del pais, 1989-1990, jugaron un papel fundamental en la preparación de una nueva ley indigena. Aliados con los otros pueblos indigenas del pais, se planteó la necesidad que el estado reconociera los derechos de los pueblos indigenas. derechos territoriales, politicos y culturales. Con la promulgación de una nueva ley indigena en 1990, se inicio una nueva etapa en la relación entre la sociedad mapuche y el estado. La creación de la Corporación Nacional de Desarrollo Indigena, creó nuevas esperanzas en torno a papel del Estado en cuanto al problema de insuficiencia de tierras y a los beneficios sociales

Ya en el periodo del gobierno militar, comenzaron a surgir los organismos no gubernamentales (ONG), comprometidos con la situación socioeconómica y cultural de los mapuche. Se inició con ellos un nuevo modo de intervención de carácter marcadamente desarrollista que aún está en pleno auge. ${ }^{5}$ La mayor parte de dichas intervenciones está orientada a la transferencia tecnológica y obtención de insumos. En menor proporción se ha dedicado fondos a saneamiento de condiciones básicas, como agua, electricidad y caminos.

Las actuales amenazas al pueblo mapuche provienen del modelo neoliberal de mercado, que impera en el pais. Las tierras indigenas están catalogadas de improductivas para la agricultura tradicional, siendo la mayor parte calificada como aptas para la industria forestal. Esto ha provocado una gran presión sobre la propiedad mapuche. Actualmente, el desarrollo de megaproyectos sobre territorio indigenas es otro punto conflictivo ${ }^{6}$. Las dificultades para armonizar una economia liberal de mercado con las economias de subsistencia característica de los mapuches rurales son

En la actualidad, se ha llegado un nivel de competencia por la clientela indigena, bastante complicada. El motivo es que los fondos de desarrolio que ol gobierno ofrece, son accesibles por medio de la presentacion de proyeclos y cle concursos

6. Una serie de contrales hidroeléctricas en la zona del Alto Bio-Bio, territorio mapuche del grupo Pewenche: el desvio de la carretera de Temuco, por sobre las ticras de las comunidades mapuche de la zona: la carretera de la costa, que esta siendo construida y cruza un amplio territorio mapuche del grupo I afquenche; la construccion de una procesadora de celulosa en la zona mapuche de Mehuin. Cfr en Internet, URL. http //www xs4all.nl/-rehue. En seccion. Noticias y acciones, articulo: Megaproyectos megaproblemas. 
evidentes. La desprotección de los derechos de indigenas sobre sus recursos naturales, está haciendo crisis frente a un modelo económico basado en la explotación indiscriminađa de recursos. ${ }^{7}$

\section{La Pastoral Indigena despuÉs del Vaticano II}

En 1962, la Diócesis de Temuco y el Vicariato Apostólico de la Araucania, crearon la Fundación Instituto Indigena con el objeto de que sirviese a la investigación, educación y a la asistencia social del pueblo mapuche. Esta iniciativa surgió de la posibilidad de acceder a fondos de desarrollo extranjeros y de la preocupación por la situación socioeconómica de las comunidades mapuche. Fue un primer paso en la retomada de una atención especifica hacia los mapuches, al menos en el área social.

A partir de 1967, bajo la dirección de los sacerdotes $E$. Theisen y $F$. Belec, la fundación comenzó a realizar actividades de evangelización directa. Iniciaron lo que hoy se conoce como "Pastoral indigena", es decir, una acción evangelizadora especifica hacia los sectores indigenas. El objetivo era "construir comunidades cristianas mapuches con el ideal de que ellas fueran a descubrir su lugar en la iglesia parroquial, diocesana y universal. ${ }^{88}$ Un elemento fundamental para esto fue que retomaron el aprendizaje del idioma. Se empeñaron en formar comunidades cristianas de carácter mapuches e iniciaron la capacitación de agentes locales como animadores y catequistas. También comenzaron el primer programa radial católico en lengua mapuche. En general procuraron ofrecer elementos más vivenciales y no tanto doctrinales, en buena parte tomados de la experiencia de la Renovación Carismática. ${ }^{y}$ Esto significó un nuevo impulso misioneros hacia las comunidades mapuche.

Los cambios pastorales que estaban aconteciendo en la iglesia latinoamericana, recogidos por los encargados de la Fundación Instituto Indigena, llevaron un nuevo modelo pastoral, centrado en la formación y acompañamiento de una "comunidad cristiana mapuche" ubicada al interior de las mismas comunidades reduccionales. El animador, un laico de la propia comunidad mapuche, comienza a ser visto como el nuevo protagonista de la pastoral. La mayor dificultad fue la falta de integración de este trabajo con el resto de la pastoral, especialmente en relación con las parroquias. Además este proceso se desarrolló casi exclusivamente en el área de la diócesis de Temuco. Las diferencias en las lineas de conducción

7 Cfr Idem, articulo de V. TOLEDO, "Todas las aguas. Notas sobre la desprotección de los derechos indigenas sobre sus recursos naturales".

$8 \quad$ F. BELEC, ¿¿Puede un mapuche llegar a ser católico?" En: Nütram, Año V, N³, 1989. p. 31.

9 Cfr A. BURGOS, "La experiencia pastoral de la Fundación Instituto Indigena. En: Seminario Nacional Pastoral Indigena. Area pastoral social de la Conferencia Episcopal de Chile. 6-8 de Octubre de 1987 pp. 84-91 
pastoral entre el Vicariato de la Araucania y la diócesis San José de Temuco impidieron un trabajo conjunto. ${ }^{10}$ Posteriormente, el modelo fue asumido también en algunos sectores del Vicariato.

En 1978-79, ante la inminente dictación de la ley de división de tierras indigenas por el régimen militar, la diócesis de Temuco impulsó mediante la organización de los Centros Culturales Mapuche la defensa de los derechos de los indigenas. Más tarde, esta organización se dividió en varios grupos, cada uno ligados a tendencias politicas diferentes, desvinculándose de la iglesia. Estas organizaciones tuvieron una importante participación a fines de los 80 , en el proceso de retorno a la democracia, especialmente en la negociación de una nueva ley indigena. El tema del reconocimiento de la identidad étnica pasó a ser el pilar fundamental de la demanda politica indigena. La tradicional demanda por tierra ganó una dimensión más ideológica y con proyección politica de largo plazo. ${ }^{11}$ Posteriormente la preocupación de la Fundación Instituto Indigena, que acompañó los primeros pasos de la organización, se desvinculó y se orientó principalmente a la promoción social directa en las comunidades rurales.

En 1979, después de la Conferencia de Obispos en Puebla, los 6 obispos de la región mapuche, Concepción, Los Angeles, Temuco, Araucania, Valdivia y Osorno, publicaron la primera carta pastoral conjunta, especifica sobre la evangelización del pueblo mapuche. En ella se reconoce la situación del pueblo mapuche con relación a la sociedad nacional y se dan lineas generales para una evangelización de la cultura y promoción integral, siguiendo básicamente las propuestas del documento de Puebla. ${ }^{17}$ Esta carta inaugura un nuevo periodo de preocupación pastoral de la iglesia católica por el pueblo mapuche.

Otro hito importante lo marcó la visita del Papa Juan Pablo II el año 1987, que dentro de su agenda incluyó un encuentro masivo con el pueblo mapuche en Temuco. Esto dio un nuevo impulso a las demandas indigenas. E) Papa se refirió directamente al tema de la identidad, que ya era claramente el nuevo derrotero del discurso mapuche:

"Al defender vuestra identidad no solo ejerceis un derecho, sino que cumplis también con un deber: el deber de transmitir vuestra cultura a las generaciones venidcras, enriqueciendo de este modo a toda la nación chilena. con vuestros valores bien

10 Cfr Entrevista Monseñor Sergio Contreras, Obispo de Temuco En: Nütram. Año VIII. N28, 45-53.

11 E. GACITÚA. Estanislao, Op. cit p. 34.

12 Evangelización del Pueblo mapuche. Carta Pastoral de los obispos de Concepción. Los Angeles, Temuco, Araucania, Valdivia, Osorno. Temuco, 4 de mayo de 1979. Policopiado, Temuco, 1979 
conocidos: el amor a la tierra, el indómito amor a la libertad, la unidad de vuestras familias." ${ }^{\text {1.3 }}$

El tema de la identidad mapuche y el reconocimiento de sus derechos, por parte de la sociedad chilena, se había tornado el eje central del discurso indigena. Esto repercutió en el ámbito religioso, y adquirió especial importancia ante la proximidad de la celebración de los 500 años de la evangelización.

El tema de la pastoral mapuche comenzó a ser debatido más ampliamente, a partir de las jornadas de pastoral indigenistas, que comenzaron en 1983, auspiciadas por la Fundación Instituto Indigena. Las mismas se transformaron a partir de 1987, por decisión de la Conferencia Episcopal, en Seminarios Nacionales de Pastoral Indigena. Curiosamente, quedaron ubicados en el Área de Pastoral Social. En 1989, la misma conferencia Episcopal, creo la "Comisión Nacional de Pastoral Indigena", coordinada por la misma Fundación Instituto Indigena. En 1992 se realizó el $1^{\circ}$ Encuentro Teológico en torno al tema la religión mapuche. Asi después de tantos siglos, se inicia el proceso de reconocimiento de la existencia y del respeto que merece la religión mapuche como tal: "Por primera vez planteamos un desafio como iglesia, reconociendo a través de esta reflexión a la religión mapuche."14

\section{Actual situación Religiosa y pastoral de los MaPUCHE EN LA ARAUCANia}

Hoy en dia existen comunidades cristianas de mapuche en todos los rincones de la Araucania, con niveles de participación en la vida litúrgica y sacramental muy variables. Es decir, hay una presencia amplia de la Iglesia Católica entre los mapuches del campo. Pero igualmente se puede afirmar, sin lugar a duda, que la religión mapuche continúa muy presente y resistiendo todo empeño de "convertirla". La gran mayoria mapuche continúan viviendo y celebrando su fe tradicional. Es cierto que muchas costumbres y ritos ancestrales se han perdido, pero el sistema religioso mapuche mantiene una firmeza y coherencia notables y continúa siendo el pilar de la identidad y la clave fundamental de la resistencia cultural.

La acción pastoral que se realiza en las comunidades mapuches en la actualidad se puede caracterizar del siguiente modo:

Todas las comunidades mapuche rurales están incluidas pastoralmente dentro de la estructura parroquial y diocesana, que responden

Discurso del Papa Juan Pablo II, en Temuco. En: Al pueblo mapuche ante la nueva legislación. Carta pastoral. Santiago, Cencosep. 1991, p. 9.

14 Comisión Nacional de Pastoral Indigena. $1^{\circ}$ Encuentro Teologico. Zona Sur. 1-2 de diciembre 1992. Policopiado. 
a divisiones territoriales y políticas absolutamente ajenas a la organización cultural y territorial mapuche y que si son afines a las estructuras sociales y politicas de la sociedad dominante. Existen equipos incipientes de pastoral mapuche, pero que actúan solo en la medida que las parroquias se lo permiten.

A las comunidades mapuches se les ofrece en las parroquias, en general, la misma catequesis sacramental y servicio religioso que a cualquier chileno de otro punto del pais. No ha prosperado en el servicio pastoral, un reconocimiento de su alteridad cultural ni de su diferencia religiosa. En efecto, ni siquiera a niveles básicos de adaptación lingüistica, litúrgica o catequética. La práctica está basada en el esquema de conversión por aculturación. Se espera que el mapuche vaya abandonando sus "costumbres" para que vaya comprendiendo y aceptando las costumbres "cristianas".

En la actualidad es posible apreciar un claro resurgimiento de la religión tradicional en la población mapuche rural y en algunos sectores urbanos. Hasta hace algunos años se hablaba del desaparecimiento. Al mismo tiempo esto contrasta con la creciente participación mapuche en las distintas confesiones cristianas evangélicas pentecostales.

Entre la adhesión y el conflicto. La Iglesia católica hace mucho tiempo que no tiene la hegemonia religiosa del pueblo mapuche, pero también es cierto que una gran mayoria se bautiza en la Iglesia Católica. Los conflictos entre esta religion tradicional y las estructuras pastorales de las iglesias locales son claramente perceptibles en la práctica pastoral. Lo más evidente, sin querer explicarlo, es el paraleiismo en que los mapuche mantienen ambos sistemas religiosos.

Entre las diferentes confesiones cristianas, especialmente las pentecostales, hay una fuerte competencia por conquistar la hegemonia religiosa en las comunidades mapuche. El efecto de la conversión de miembros de una comunidad tradicional a alguna iglesia evangélica conlleva siempre una crisis ya que muchas iglesias prohiben toda participación de sus miemros en los ritos tradicionales y en las actividades sociales o recreativas de las familias. Hoy en dias son escasas las comunidades que no tengan una o más iglesias pentecostales en su alrededor o en su interior.

Un elemento relativamente nuevo es la emergencia de un mapuche urbano y de sus organizaciones, que reivindicando espacios propios en las ciudades, marcan un nuevo modo de presencia y de participación de los mapuche en el contexto nacional. Estos grupos, en general críticos de todo el sistema que los discrimina, revisan igualmente la presencia y la acción de las iglesias en las comunidades mapuche. Entre ellos se está dando una 
reformulación de la identidad ritual y de la comprensión del ser mapuche en la ciudad (proceso de reetnificación de las generaciones urbanas) ${ }^{15}$.

\section{E. Persistencia de situación Neocolonial}

El marco de intervención pastoral de la Iglesia aparece todavia claramente dominado por rasgos coloniales:

\section{La Tierra.}

Las comunidades mapuche rurales se encuentran sometidas a lo que restó del régimen de "reducciones" impuesto el siglo XIX. La constitución de la propiedad privada rural en la región de la Araucania es un proceso reciente e inconcluso. Las tierras indigenas siguen siendo motivo de conflicto. A la insuficiencia se sumó la amenaza de la expansión de la industria forestal, de los proyectos hidroeléctricos, las industrias y las carreteras, que se proyectan en tierras indigenas. La mayor parte de las comunidades rurales no logra niveles de vida aceptables con su economía de subsistencia. Tampoco logra competir a nivel de mercado por estar reducidos a tierras degradadas, escasas y no contar con recursos suficientes para implementar cambios substanciales. Las Iglesia locales no han asumido posiciones claras en el conflicto de tierras ni en el proceso de transformación económico que se está imponiendo al campesinado mapuche.

\section{El Idioma.}

El castellano sigue siendo el idioma exclusivo de toda intervención pastoral y litúrgica por parte de la Iglesia. A eso se suma el hecho de que la Iglesia católica continúa teniendo una fuerte presencia a través de escuelas rurales en gran parte de la región mapuche, las que trabajan con el modelo monocultural de educación de la sociedad nacional. En los últimos años hay esfuerzos por asumir una educación bilingüe. Pero aủn se mantiene a nivel de "traducción" del sistema nacional.

En el tema especifico de traducción biblica, este ha sido casi exclusivamente lievado por las iglesias protestantes. El Instituto Lingüistico de Verano comenzó en 1985 y terminó a fines de 1996 el trabajo de traducción del nuevo testamento en lengua mapuche. La publicación se realizó, con el apoyo de las Sociedades Biblicas Unidas en marzo de 1997. La Iglesia Católica local se mantuvo al margen de este trabajo.

Cfr R. CURIVIL. Los cambios culturales y los procesos de re-etwificación entre los mapuces urbanos: un ostudio de caso. Tesis para optar al grado de magister en ciencias sociales. Universidad Academia de Humanismo Cristiano. Santiago 1994. Dei mismo autor: Estudio de identidad mapuche en la comuna de Cerro Navia. Santiago, 1997. Policopiado. 


\section{La Religión.}

Continúa el desconocimiento y la desconfianza de parte de la Iglesia hacia la religión tradicional mapuche. En encuentros pastorales con lideres religiosos tradicionales, estos han expresado claramente su disconformidad con los atropellos a su religión y el desconocimiento a su autoridad. Rechazan la folclorización de sus tradiciones religiosas en las liturgias católicas y esperan un cambio de actitud."

\section{F. Algunas conclusiones desde la Misionologia}

Para la iglesia resulta vital preguntarse por el modo como enfrentar el desafios de anunciar el Evangelio al pueblo mapuche. La situación es compleja y precisa primero que nada clarificar el actual escenario mapuche. Hay que diferenciar entre los que quieren ser cristianos y los que no quieren serlo, entre los que procuran comprender el evangelio desde su cultura mapuche, sin dejar de ser tales y los que sólo desean un dialogo interreligioso, o que simplemente rechazan toda relación con la iglesia. ${ }^{17}$

Segundo, hay que reconocer que estamos en un punto sin retorno, es decir, ya existe una vivencia cristiana incorporada por el pueblo mapuche en general. No se puede tratar de deshacer una evangelización, por muchos errores que haya contenido. Tampoco se pueden abandonar las comunidades cristianas, como se llegó a insinuar en algunos momentos (moratoria misionera). El problema es si es posible continuar cometiendo los mismos errores, los mismos atropellos, confiando el anuncio del evangelio al proceso de aculturación.

Tercero, es que el tema de la evangelización de la cultura o inculturación del evangelio, recogido directamente en Sto. Domingo y traspasado a las orientaciones pastorales de las iglesias locales, corre el serio peligro de quedarse en el discurso. Implementar un verdadero cambio en la forma en que las iglesias locales se relacionan con el pueblo mapuche, con su religión tradicional es aún una tarea pendiente.

El mapuche aparece siempre como objeto de una acción pastoral, en una relación de agente y paciente. Por esto, primero que nada, la acción misionera de la Iglesia debe ser evaluada por el espació que ella ha sido capaz o no de conceder al protagonismo indigena. Observamos a lo largo de la historia de la acción misionera, una desconfianza radical de la Iglesia y de los mișioneros en la capacidad mapuche de orientar y realizar sus propios procesos históricos. Del mapuche engañado por el demonio y la

\footnotetext{
16

Cfr P. LINCOPAN, et alter La evangelización y la religiosidad do los mapuches. Santiago. IMPRU, 1992.

Para este punto, Cfr E LOPEZ, "Teologias indias de hoy". En Enctentro dialogo sobre motodologia teológica latinoamericana. México. 17 al 21 de mayo de 1993. Policopiado.
} 
superstición, que precisa de salvación, se pasó al mapuche infantil e ignorante precisando de un padre responsable que lo educara. Del mapuche flojo y atrasado, que precisaba desaparecer o ser integrado a la civilidad, se pasa al mapuche pobre y subdesarrollado que precisa de quien lo introduzca en la modernidad.

Los reclamos de autonomia y la demanda por el reconocimiento de su derecho a ser diferente, de desarrollar su cultura, su religión, su proyecto histórico, fueron siempre apagados por la intolerancia de una sociedad que no aceptó y todavia no acepta convivir, relacionarse, con una sociedad diferente. Parte substancial de esa intolerancia, esta anclada en una justificación religiosa. La cultura cristiana occidental está convencida de ser la única capaz de expresar plenamente lo humano y lo divino. De ahi que es fundamental ef reconocimiento de la presencia de Dios en la historia y cultura del pueblo mapuche. $Y$ no solo Dios como Creador, que se pierde en los origenes, sino el Dios de Jesucristo, trinitario, presente en los anhelos profundos de vida plena, en su lucha por alcanzar la libertad, la dignidad, en la búsqueda de trascendencia, de sentido. Eso significa reconocer al pueblo mapuche su capacidad y su derecho de protagonizar su propio proyecto histórico, distinto al que se le ha querido imponer por siglos. La evangelización no puede ser un intento de sustituir un proyecto con otro. El evangelio nació a horcajadas del proyecto histórico judío, pero fue capaz de trascenderlo, y en eso está su fuerza histórica. Cristo no se agotó en las dimensiones de un héroe cultural judio. El cristianismo no es una religión superior que viene a imponerse sobre otras religiones inferiores.

Eso nos coloca de nuevo en la pregunta esencial de ¿Qué es la evangelización? Después del Vaticano II nos ha quedado mucho más claro que el evangetio no es cultura ni puede pretender llegar a serlo (GS. 57-58) ¿Que es lo que se pretende cuando se habla de evangelizar una cultura determinada? Evangelizar una cultura no puede significar infiltrarla en puntos neurálgicos y obtener el control de sus comportamientos religiosos. Evangelizar es primero que nada anunciar el reino de Dios. Eso significa confrontar el proyecto histórico de un pueblo con la perspectiva de la voluntad de Dios, no como una contrapropuesta al proyecto humano, pues este proyecto ya es, en cuanto vocación propia humana, obra de la misma voluntad de Dios. Anunciar el reino de Dios es potenciar la pregunta por el sentido en las utopias propias de cada cultura, es ahondar en el misterio de la búsqueda inagotable de libertad, es recuperar la perspectiva de los pobres y marginados desde la opción explícita de Dios manifestada en Jesús, es recoger y relevar la sabiduria y la fuerza que se esconde en el sufrimiento presente en toda situación humana. Al mismo tiempo es aceptar el escándalo, manifestado en la cruz, que este anuncio provoca. Escándalo, porque confronta con el sentido radical del triunfo después de la muerte, del perdón y del amor al enemigo, del poner la otra mejilla frente a los violentos, del protagonismo de los pobres y de los pequeños. Escándalo porque afirma la presencia de Dios en los despreciados, en el crucificado. En último 
término, se trata de poner toda la actividad humana a la luz del amor gratuito del Dios revelado en Jesucristo.

Entonces es evidente que el evangelio no viene a imponer o diseñar un modelo de sociedad tal o cual. tampoco viene a asegurar el futuro de esta o de aquella cultura por sobre las otras. El evangelio precisa de la hospitalidad de una comunidad humana. del protagonismo de sus miembros y de la riqueza de su cultura, para poder brindar su fuerza liberadora. Sin el protagonismo de sus miembros. únicos capaces de desplegar su proyecto histórico y de recrear la propia cultura. no hay evangelización. Habrá resistencia, sometimiento, pero no inculturación del evangelio. Sin la riqueza de la cultura, si esta es destruida. el evangelio se queda sin carne, sin lenguaje. Se lo convierte a lo sumo en una ideologia. Sin la hospitalidad, no hay encuentro. no hay dialogo. La evangelización es posible solo a partir de la hospitalidad y nunca a partir de la imposición o de la necesidad.

Eł peligro será siempre confundir el evangelio con la propia cultura. Pero la relación de ambos será necesariamente dialéctica, segun el modelo de encarnación y crucifixión. de la inculturación y del escándalo. Asi la evangelización del pueblo mapuche. pasa por su proyecto histórico. codificado en su cultura. cuyos protagonistas sólo pueden ser los mismos mapuche.- 